Artigo de Revisão

Hegemonia - Revista Eletrônica do Programa de Mestrado em Direitos Humanos, Cidadania e Violência/Ciência Política do Centro Universitário Unieuro

ISSN: 1809-1261

UNIEURO, Brasília, número 27 (Especial), 2019, pp. 128-160.

Recebido em: 19/9/2018

Avaliado em: 6/10/2018

Aprovado em: 26/11/2018

\title{
INTERNAÇÕES E CUSTOS HOSPITALARES: ANÁLISE COMPARATIVA DE UM SISTEMA DE AUTOGESTÃO COM O SISTEMA ÚNICO DE SAÚDE
}

Débora Bleza Santos ${ }^{1}$, Carla Pintas Marques ${ }^{2}$ e Marcos Takashi Obara ${ }^{3}$

Resumo: Embora o sistema público de saúde brasileiro seja aberto a toda população, a legislação permite que o sistema privado também ofereça de serviços assistência à saúde. Este pode ocorrer na contratação de planos de saúde, onde o contratante tem direito à uma carteira de serviços, desde que o beneficiário contribua mensalmente. O presente estudo compara as internações do sistema público e do sistema de autogestão e os seus respectivos custos, por Capítulo CID-10, no ano de 2016, discutindo também o perfil de cada população atendida. Ambos sistemas tem o mesmo financiamento, entretanto há diferença no público atendido e nos serviços prestados, e esse fator determina o tempo de permanência do beneficiário/usuário em cada sistema. Identificou-se que o tempo médio de internação dos usuários no Sistema Único de Saúde é o dobro do encontrado no plano de saúde na modalidade de autogestão. No que se refere aos custos, o sistema de autogestão apresentou custos exorbitantes ao se comparar com o SUS com um dos capítulos do CID-10 tendo custo de mais de 75 vezes maior. Pode-se notar que o perfil do beneficiário de autogestão é de pessoas com idade avançada, mostrando também os principais motivos de internação no setor. A União repassa valores mais altos ao serviço privado do que ao SUS, mesmo com o serviço privado assistindo uma quantidade reduzida da população. A alteração na forma de repasse do dinheiro público aos sistemas privados poderia ajudar o fortalecimento do sistema público, com a melhoria dos atendimentos prestados, dando maior aporte tecnológico ao usuário.

Palavras-chave: autogestão, Sistema único de saúde, saúde pública, internações, custos, plano de saúde, saúde suplementar.

Abstract: Although the Brazilian health system is available to the whole population, the legislation in the country allows the private system to offer health care services. It can happen with the hiring

\footnotetext{
${ }^{1}$ Graduada em Saúde Coletiva pela Universidade de Brasília.

${ }^{2}$ Doutoranda em Saúde Coletiva pela Universidade de Brasília.

${ }^{3}$ Doutor em Saúde Pública e Professor Adjunto da Universidade de Brasília.
} 
Artigo de Revisão

Hegemonia - Revista Eletrônica do Programa de Mestrado em Direitos Humanos, Cidadania e Violência/Ciência Política do Centro Universitário Unieuro

ISSN: 1809-1261

UNIEURO, Brasília, número 27 (Especial), 2019, pp. 128-160.

of health insurance, where the company gives to the client a list of services that he can access, once there is a monthly contribution. This study compares hospitalizations of the public system with the self-management system, and then the respective costs based on the chapter of ICD-10, in 2016, discussing also the profile of each population. Both systems have the same backing, however there are differences in the attended public and services. This factor determines the permanence of the user in each system. The average time of permanence observed of the Sistema Único de Saúde user is the double of the self-management system user. The cost of the self-management is exorbitant when compared with SUS, with one of the ICD-10 chapter being 75 times higher. The profile of the self-management users is about older people, which shows the main causes of hospitalization. The government forwards a bigger amount to the private service instead of SUS, even with a reduced population. The change in the way of forwarding public money to private systems could help and strengthen the public system, with the improvement of the services rendered, giving greater technological contribution to the user.

Key-words: self-management, Sistema único de saúde, public health, hospitalization, cost, supplementary health, health insurance.

\section{INTRODUÇÃO}

A saúde no Brasil é um direito garantido à população pela Constituição Federal de 1988, onde o Estado tem papel de provedor desse serviço, oferecendo condições básicas para a população, em um sistema de saúde.

Na lei 8.080, que regulamenta as ações e serviços de saúde, há abertura para que além da saúde pública - o Sistema Único de Saúde - existam outras formas de oferta de serviço de saúde, como a saúde suplementar, nessa modalidade, as operadoras de planos de saúde dão a oportunidade aos cidadãos de optar entre o serviço público ou privado, que quando escolhendo este último, na forma de plano de saúde, o cidadão tem acesso à uma rede credenciada para ter atendimento.

No ano de 1998, o Congresso Nacional aprovou a Lei n. 9.656, que dispõe sobre os planos e seguros privados de assistência à saúde, definindo os serviços a serem prestados, os requisitos a serem cumpridos para seu funcionamento e direitos ao beneficiário, como a cobertura de consultas médicas quando incluir atendimento ambulatorial.

O Ministério da Saúde - MS, em 2000 estabeleceu a criação da Agência Nacional de Saúde Suplementar - ANS, para fiscalizar e fazer-se cumprir a Lei citada anteriormente. A ANS tem por finalidade promover a defesa do interesse público na assistência suplementar à saúde, regulando e fiscalizando as operadoras quanto às relações com prestadores e consumidores (Brasil, 2000). 
Artigo de Revisão

Hegemonia - Revista Eletrônica do Programa de Mestrado em Direitos Humanos, Cidadania e Violência/Ciência Política do Centro Universitário Unieuro

ISSN: $1809-1261$

UNIEURO, Brasília, número 27 (Especial), 2019, pp. 128-160.

Em dezembro de 2016, segundo a ANS, 47.898 .787 milhões de pessoas possuíam planos privados de assistência médica, com ou sem cobertura odontológica; quanto aos planos privados exclusivamente odontológicos, esse número era de 22.031.342 milhões de pessoas (Brasil, 2016).

Para o serviço de saúde suplementar, são utilizados alguns termos de forma recorrente: plano privado de assistência à saúde, que caracteriza-se como a prestação do serviço de saúde; operadora de plano de assistência à saúde, sendo a pessoa jurídica que opera o serviço de saúde; e carteira, como o conjunto de serviços a serem disponibilizados na contratação do serviço (Brasil, 1998).

As operadoras de planos de saúde, podem ser classificadas em administradora de benefícios, regulamentada pela Resolução Normativa - RN, no 196 de 2009; cooperativa médica, cooperativa odontológica, autogestão, medicina de grupo, odontologia de grupo, ou filantropia, dispostas na Resolução de Diretoria Colegiada - RDC, nº 39 de 2000.

A modalidade de autogestão, possui administração própria e opera junto a convênios com planos privados de assistência à saúde, e também deve exercer ações de promoção à saúde. $\mathrm{O}$ serviço deve ter uma rede própria, credenciada, contratada ou referenciada, para suprir as necessidades do seu beneficiário (Brasil, 2006).

O monitoramento do perfil dos beneficiários de planos de saúde é necessário para que ações com maior eficácia sejam implementadas para melhoria na saúde, não devendo depender a saúde suplementar apenas de assistência, mas também da prevenção e promoção à saúde.

Dados do Vigitel do ano de 2016 (Brasil, 2017), mostrou melhoria dos hábitos da população beneficiária dos planos de saúde. Na variação temporal da realização da pesquisa, houve redução da porcentagem de usuários fumantes, em média de 0,62 pontos percentuais por ano (de 2006 a 2016), este dado inclui todos os estados e o Distrito Federal.

Outro dado que reforça a mudança do comportamento da população, é o aumento da porcentagem dos beneficiários que são ativos no tempo livre (1,17 pp) e a redução do consumo de refrigerantes em cinco ou mais dias da semana (1,33 pp no período), mostrando que no período que foi aplicada a pesquisa, houve crescimento do cuidado com a saúde (Brasil, 2017).

Entretanto, ainda na análise realizada pelo Vigitel, observou-se evolução dos indicadores de excesso de peso e da obesidade. Este comportamento da população, se enquadra como fator de 
Artigo de Revisão

Hegemonia - Revista Eletrônica do Programa de Mestrado em Direitos Humanos, Cidadania e Violência/Ciência Política do Centro Universitário Unieuro

ISSN: $1809-1261$

UNIEURO, Brasília, número 27 (Especial), 2019, pp. 128-160.

risco para doenças crônicas, acarretando futuramente, em internações e outros cuidados que o beneficiário deverá adotar, e consequentemente, em custos para o plano de saúde (Brasil, 2017).

Embora o beneficiário contribua com o financiamento do plano de saúde, há destinação de recurso público para os planos e seguros de saúde. Segundo Bahia (2009), o Brasil destina o dobro de recursos ao sistema privado. Os preços médios de consultas e internações realizados pelas modalidades de serviços de saúde, são de três a seis vezes a maiores que os das instituições públicas (Bahia, 2009).

A importância da discussão dos gastos com saúde no país se dá pela destinação de recurso público, e a possibilidade de o beneficiário ser assistido duas vezes - pelo seu plano e também pelo SUS.

Na graduação em Saúde Coletiva, o Sistema Único de Saúde é explorado pelos alunos, onde há aplicação da teoria e a realização de três estágios obrigatórios, passando por cada ponto de atenção. Entretanto o conhecimento sobre planos de saúde e saúde suplementar são inexistentes, deixando a lacuna para o futuro profissional.

Embora o conhecimento adquirido durante a graduação prepare o profissional para atuar em todas as esferas de gestão em saúde, há pouca inserção no sistema privado e em planos de saúde, instigando sobre seu funcionamento e formas de contribuição na área.

A expertise em montar o perfil e conhecer a população que é de responsabilidade do gestor, permite que ações sejam tomadas para prevenir doenças e principalmente, promover a saúde. Nos trabalhos executados na graduação, quando há busca por dados em saúde que retratem a realidade, os mesmos, muitas vezes, encontram-se incompletos.

A aplicação desta análise ao sistema privado de saúde, à modalidade de autogestão, levanta o questionamento de: quando o sistema é privado, há completude nos dados? Como se dá este retrato da realidade? Apesar de ser um sistema privado, as pessoas adoecem pelos mesmos motivos que no sistema público? Quais são as doenças que mais internam e com maior custo para os respectivos sistemas?

O Vigitel Brasil 2016, mostrou que houve melhora nos hábitos dos usuários pesquisados, e que este perfil se encontra em transição demográfica. Essa transição também foi acompanhada pelo sistema estudado? 
Artigo de Revisão

Hegemonia - Revista Eletrônica do Programa de Mestrado em Direitos Humanos, Cidadania e Violência/Ciência Política do Centro Universitário Unieuro

ISSN: $1809-1261$

UNIEURO, Brasília, número 27 (Especial), 2019, pp. 128-160.

Outro fator estimulante para a pesquisa, é a ausência de estudos similares, para comparação de custos e causas de internações nos sistemas de saúde.

A pergunta de pesquisa para o estudo se refere à caracterização e ao conhecimento do perfil do usuário desse sistema de saúde, sendo "qual o perfil das principais causas de internação no sistema de autogestão e os custos associados a essas internações?”.

O estudo teve como objetivo geral analisar as internações de um plano de saúde autogestão - em exercício no Sistema Integrado de Saúde gerido por um órgão legislativo federal, e comparar os dados obtidos junto ao Sistema Único de Saúde, no ano de 2016.

Além da análise das internações, foi verificado o número de internações por capítulo CID10 no referido plano de autogestão; analisados os custos referentes às internações por capítulo CID-10 no plano e as internações e seus respectivos custos comparadas com as internações ocorridas no Sistema Único de Saúde.

Os Sistemas de Saúde

Para Brito (2008), a transição demográfica é um fenômeno condicionado pelas condições históricas dos países. No Brasil, esse movimento se iniciou nos anos 70, e teve grande influência da mudança da população do campo para a cidade. A alteração da estrutura etária, é o principal marco da transição demográfica, onde, foi observado que houve redução da taxa de natalidade e também da taxa de mortalidade (VASCONCELOS, GOMES, 2012).

Vasconcelos e Gomes (2012), observaram que a esperança de vida no Brasil teve aumento, tendo em 2010, valores maiores que 70 anos. A transição demográfica brasileira, pode ser observada através do gráfico 1 : 
Artigo de Revisão

Hegemonia - Revista Eletrônica do Programa de Mestrado em Direitos Humanos, Cidadania e Violência/Ciência Política do Centro Universitário Unieuro

ISSN: $1809-1261$

UNIEURO, Brasília, número 27 (Especial), 2019, pp. 128-160.

Gráfico 1 - Pirâmide etária absoluta. Brasil 2005 - 2030.

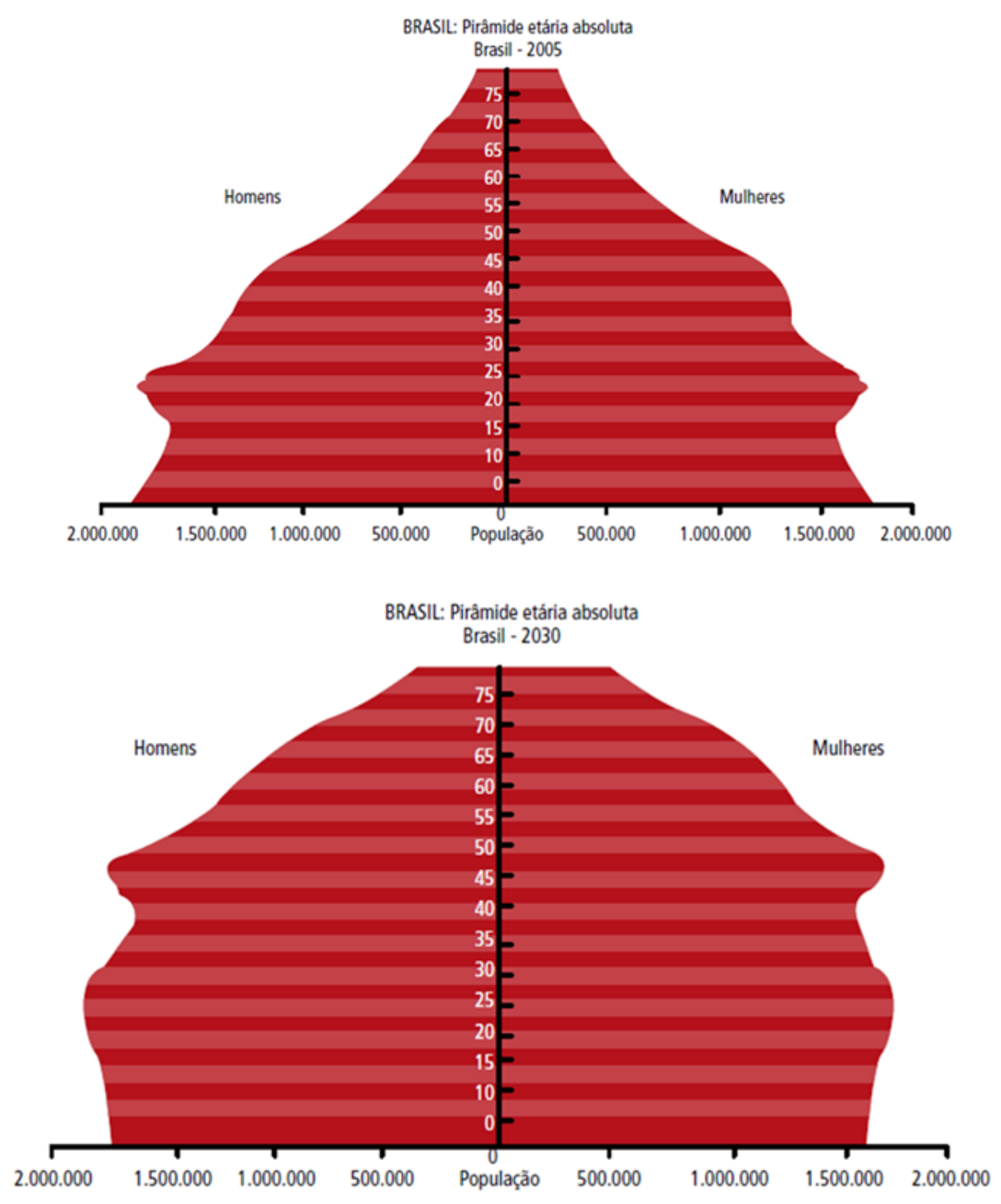

Fonte: Mendes, 2011.

O processo de transição demográfica, influencia também a transição epidemiológica. A transição epidemiológica, evidencia mudanças ocorridas na distribuição das condições de saúde, acarretando em morbidade e mortalidade dos cidadãos (Brasil, 2015a).

No Brasil e no mundo, as taxas de fecundidade diminuíram, e através dos cuidados em saúde, a expectativa de vida da população aumentou. De tal forma, a mortalidade por doenças infecciosas e parasitárias foi reduzida, e as condições crônicas de saúde aumentaram (Vasconcelos, Gomes, 2012; Mendes, 2011).

Segundo Mendes (2011), as condições crônicas de saúde, interferem diretamente na 
Artigo de Revisão

Hegemonia - Revista Eletrônica do Programa de Mestrado em Direitos Humanos, Cidadania e Violência/Ciência Política do Centro Universitário Unieuro

ISSN: $1809-1261$

UNIEURO, Brasília, número 27 (Especial), 2019, pp. 128-160.

qualidade de vida dos indivíduos, causam mortes prematuras e geram custos às famílias e aos sistemas de saúde.

Sistemas de saúde são construções sociais que tem por objetivo, garantir meios adequados para que os indivíduos obtenham assistência, frente a riscos sociais, econômicos e ambientais que eles enfrentam (Elias, 2005). Um sistema de serviços de saúde é formado por componentes e funções principais; podem apresentar-se de forma fragmentada e/ou integrada. Os sistemas fragmentados tendem a se voltar para a atenção principal às condições e aos eventos agudos, enquanto os sistemas integrados tendem a atuar equilibradamente sobre as condições agudas e crônicas (Paim, 2008; Mendes, 2011).

As condições agudas de saúde, tem duração limitada, manifestação abrupta e a maioria das intervenções são efetivas, levando à cura da situação. As condições crônicas, tem início gradual, com causas múltiplas, e as intervenções propiciam o cuidado com o usuário. As condições crônicas, não são apenas as doenças, como hipertensão, mas também abarcam doenças como HIV/Aids (Conass, 2006). Este fator, caracteriza a dupla carga de doenças, onde há acúmulo de agravos para a população, com doenças infecciosas e crônicas; na tripla carga, há acréscimo das causas externas (Mendes, 2011).

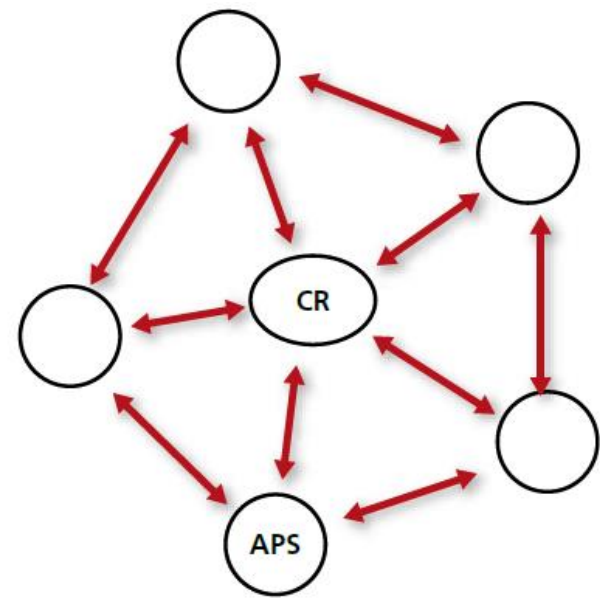

CR: Complexo regulador

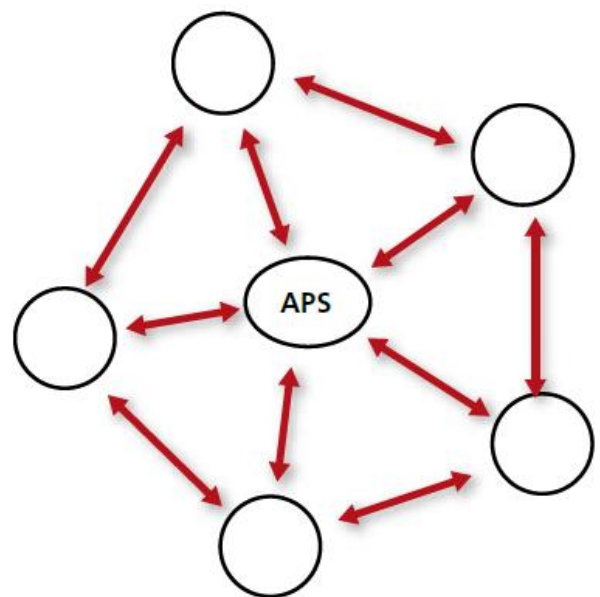

APS: Atenção primária à saúde

Figura 1 - Redes de atenção às condições agudas e crônicas. Fonte: Mendes (2011).

O sistema de saúde fragmentado tende a ter um complexo regulador, visto que devido à 
Artigo de Revisão

Hegemonia - Revista Eletrônica do Programa de Mestrado em Direitos Humanos, Cidadania e Violência/Ciência Política do Centro Universitário Unieuro

ISSN: $1809-1261$

UNIEURO, Brasília, número 27 (Especial), 2019, pp. 128-160.

urgência da demanda, é inviabilizado que o paciente seja atendido na Atenção Primária. O complexo regulador será comandado pelo médico que o atenderá nesta situação. No sistema de saúde integral, o paciente é acompanhado pela Atenção Primária, onde o quadro do paciente é controlado, e evita-se que a doença, quando possível, tome um quadro agudo (Mendes, 2011).

O Sistema de Saúde Brasileiro

No Brasil, nos anos de 1960, o sistema público de saúde se dividia entre a Previdência Social e a saúde pública. O sistema previdenciário era voltado à saúde individual dos trabalhadores formais, onde através de uma contribuição, esse trabalhador tinha direito à consultas e tratamento para o problema de saúde. A contribuição era destinada à institutos de pensão, que atendia principalmente a zona urbana; além disso, as ações eram de caráter assistencial; a saúde pública, era direcionada às zonas rurais e áreas com maior vulnerabilidade, com ações de prevenção da saúde, era responsabilidade do Ministério da Saúde (Paiva, Teixeira, 2014).

A organização e contratação de grupos que proviam assistência à saúde, teve valorização junto ao processo de industrialização que envolvia diversos países. Além de oferecer segurança ao empregador - que não seria prejudicado com ausência do funcionário - também permitia um melhor atendimento ao empregado (Sestelo, Bahia, 2014). No governo militar, decretos liberaram a contratação de empresas médicas e serviços de saúde, proporcionando abertura para que houvesse crescimento do setor, principalmente após a crise do petróleo de 1978 (Bahia, Scheffer, 2010).

Como parte da população não recebia assistência à saúde, houve grande mobilização da sociedade pela reforma do sistema de saúde (Paiva, Teixeira, 2014). A VIII Conferência Nacional de Saúde foi marco determinante para a transformação do sistema de saúde, nela se discutiu a instituição da saúde como direito de cidadania e dever do Estado; a compreensão da determinação social no processo saúde doença e a reorganização do sistema de atenção, integrando a medicina previdenciária à saúde pública (Paiva, Teixeira, 2014; Eibenschutz, 1995).

O SUS foi criado através da promulgação da Constituição Federal, em 1988, sendo definido no Art. 198 como "ações e serviços públicos de saúde integram uma rede regionalizada e hierarquizada”. Além da criação do SUS, a Constituição Federal, também permite que a assistência 
Artigo de Revisão

Hegemonia - Revista Eletrônica do Programa de Mestrado em Direitos Humanos, Cidadania e Violência/Ciência Política do Centro Universitário Unieuro

ISSN: $1809-1261$

UNIEURO, Brasília, número 27 (Especial), 2019, pp. 128-160.

à saúde seja oferecida pela iniciativa privada (Art. 199), podendo participar do sistema de saúde, de forma complementar. (Brasil, 1988).

A regulamentação do SUS aconteceu através da lei n. 8.080 de 1990. No art. $2^{\circ}$, a saúde é definida como "direito fundamental do ser humano, devendo o Estado prover as condições indispensáveis ao seu pleno exercício [...] o dever do Estado não exclui o das pessoas, da família, das empresas e da sociedade" e o Sistema é definido no art. $4^{\circ}$ como conjunto de ações e serviços de saúde prestado por órgãos públicos, podendo ter participação da iniciativa privada em caráter complementar (Brasil, 1990).

Embora tenha mais de vinte anos, o SUS está em constante mudança, desde que sejam aprovadas pelos três entes federativos - Ministério da Saúde, Conselho Nacional de Secretários de Saúde (Conass) e Conselho Nacional de Secretários Municipais de Saúde (Conasems). O modelo de gestão do SUS, é definido como federalismo brasileiro, cooperativo e hegemonicamente intraestatal, apresentando elementos de competição e cooperação (Brasil, 2006).

Como a gestão do SUS é tripartite, o financiamento obedece ao mesmo modelo, com recursos destinados pela União, Estados e Municípios. Segundo o CONASS (2006), em análise temporal (2000 a 2004) a maior concentração dos recursos foi para o Ministério da Saúde (49,9\% no último ano analisado), seguido pelos Estados (25,6\%) e os municípios (24,5\%), expressando problemas do modelo atual de gestão do sistema.

Outro fator agravante no repasse de verba, é a destinação dos recursos para condições agudas, fazendo com que o indivíduo portador de uma condição crônica, só receba tratamento quando sua condição está em estado agudo. Ademais, há grande perda econômica para o país, principalmente com óbitos (Conass, 2006).

\section{A Saúde Suplementar}

Embora o sistema público de saúde brasileiro ofereça cobertura à toda população, e a saúde seja um dever do Estado, como exposto, há opção de se pagar um plano ou seguro de saúde para que se tenha assistência médica, esta ação é chamada de saúde suplementar. Esta possui um financiamento privado, com subsídios públicos, e gestão privada regulada pela Agência Nacional 
Artigo de Revisão

Hegemonia - Revista Eletrônica do Programa de Mestrado em Direitos Humanos, Cidadania e Violência/Ciência Política do Centro Universitário Unieuro

ISSN: $1809-1261$

UNIEURO, Brasília, número 27 (Especial), 2019, pp. 128-160.

de Saúde Suplementar (ANS) (Pietrobon, Prado, Caetano, 2008). O SUS tem contratos com instituições privadas, para que a população tenha atendimento, como é previsto na constituição, mas alguns indivíduos e empresas optam pela contratação de planos para obter maior cobertura.

Em 1998, pela Lei n. 9.656, foram regulamentados os planos e seguros privados de assistência à saúde, sendo a prestação continuada de serviços de saúde, por prazo indeterminado, escolhido pelo consumidor.

Os planos são regulados pela ANS, como citado anteriormente, esta foi criada pela Lei n. 9.961 de 28 de janeiro de 2000, tendo finalidade de promover o interesse público na assistência suplementar à saúde, regulando as operadoras na prestação de serviços e desenvolvimento das ações de saúde no país; ressaltando junto às operadoras, os direitos e interesses dos beneficiários, e evitando que as mesmas obtenham vantagens, proporcionando assistência à saúde adequada ao usuário (Pietrobon, Prado, Caetano, 2008).

A Lei dos planos de saúde, permite que todas as pessoas sejam elegíveis a contratar o serviço, e os planos devem oferecer atendimento e cobertura para todos agravos constantes na CID, proibindo que idade, deficiência ou doença sejam fatores de exclusão do beneficiário (Bahia, Scheffer, 2010).

Com a regulamentação da ANS, através da Resolução da Diretoria Colegiada n. 39 de 27 de outubro de 2000, definiu-se que as operadoras dos planos de saúde deveriam se classificar em uma das modalidades: administradora; cooperativa médica; cooperativa odontológica; autogestão; medicina de grupo; odontologia de grupo; ou filantropia.

A modalidade administradora de benefícios é caracterizada pela contratação por pessoa jurídica, de plano coletivo que presta assistência à saúde (Brasil, 2009). Cooperativa médica, é a sociedade de pessoas sem fins lucrativos, operando planos privados de assistência à saúde. Já a cooperativa odontológica, operam exclusivamente para planos odontológicos (Brasil, 2000b).

A medicina de grupo, caracteriza empresas que operam planos privados de assistência à saúde, mas que não se enquadram nas modalidades citadas anteriormente, do mesmo modo ocorre com a odontologia de grupo (Brasil, 2000b).

A RN n. 315 de 28 de novembro de 2012, dispõe sobre a modalidade de filantropia. Nelas encaixam-se as entidades sem fins lucrativos que operam planos privados de assistência à saúde, 
Artigo de Revisão

Hegemonia - Revista Eletrônica do Programa de Mestrado em Direitos Humanos, Cidadania e Violência/Ciência Política do Centro Universitário Unieuro

ISSN: $1809-1261$

UNIEURO, Brasília, número 27 (Especial), 2019, pp. 128-160.

com certificado de entidade beneficente junto ao Ministério competente (Brasil, 2012a).

Assim, a Resolução Normativa (ANS) n. 137 de 14 de novembro de 2006, no art. $2^{\circ}$, retrata a autogestão em planos de saúde como pessoa jurídica de direito privado, que por intermédio do departamento de recursos humanos, opera plano privado de assistência à saúde; autogestão também pode ser a pessoa jurídica sem fins econômicos, opera plano privado de assistência à saúde exclusivamente, ou podendo ser exercida também na forma de associação.

Segundo Dias (2004), as empresas de autogestão segmentam-se em: patrocinadas - entidade de autogestão que responsabiliza-se pelo Plano Privado de Assistência à Saúde destinado, a oferecer cobertura aos empregados ativos, aposentados, pensionistas ou ex-empregados, bem como a seus respectivos grupos familiares definidos, limitado ao terceiro grau de parentesco consanguíneo ou afim, de uma ou mais empresas, e que possuam gestão própria; não patrocinadas: são as entidades de autogestão que não se classificam como patrocinada. Operam por meio de rede de profissionais e instituições diretamente credenciadas.

As autogestões, segundo Sestelo e Bahia (2014), constituem o segmento não comercial da área de planos de saúde, essa diferença, se dá pelas empresas que prestam serviço de saúde - são conveniadas.

O financiamento da modalidade autogestão pública, é fundamentado pelo Artigo 12, da Lei n. 4.320 de 17 de março de 1964, onde a transferência de recursos públicos para outras entidades pode ser caracterizada como subvenções, auxílios ou contribuições. Assim, a autogestão recebe auxílio do poder público, repassado pela União e também, contribuição mensal dos seus beneficiários. Posteriormente, há prestação de contas da empresa junto ao órgão competente, nessa conjuntura, à ANS (Brasil, 1964).

O cuidado em saúde, apesar de ser oferecido por operadoras do mesmo "tipo", é heterogêneo, visto que a qualificação do provedor, a relação que a operadora e o provedor do serviço desenvolvem com o cliente, é particular de cada organização. Essa relação do sistema de prestar saúde, interfere de maneira direta na dinâmica do mercado de planos de saúde (Brasil, 2015b).

Algumas operadoras de planos de saúde, podem ser citadas como cases de sucesso, a exemplo da Caixa de Assistência dos Funcionários do Banco do Brasil (CASSI), uma operadora de 
Artigo de Revisão

Hegemonia - Revista Eletrônica do Programa de Mestrado em Direitos Humanos, Cidadania e Violência/Ciência Política do Centro Universitário Unieuro

ISSN: $1809-1261$

UNIEURO, Brasília, número 27 (Especial), 2019, pp. 128-160.

autogestão que surgiu na década de 1940 e até hoje está no mercado (Sestelo, Bahia 2014). O segmento de autogestão é representado pela UNIDAS, associação sem fins lucrativos, criada em 2002. A associação atua junto às agências reguladoras e os outros segmentos da saúde suplementar (Unidas, 2017).

Em 2013, o perfil do beneficiário do plano de saúde, contratava mais operadoras de medicina em grupo, seguido por cooperativas médicas e autogestões. As cooperativas médicas, oferecem o serviço no interior e nas capitais do país, e as autogestões, oferecem o serviço apenas aos seus funcionários e respectivos dependentes, reduzindo o número atendido de pessoas (Brasil, 2015b).

Como o Estado não tem controle direto da gestão das operadoras de saúde, a ANS criou o Programa de Qualificação da Saúde Suplementar, que monitora e avalia anualmente a qualidade das operadoras de planos privados de saúde, através do Índice de Desempenho da Saúde Suplementar (IDSS), avaliando as operadoras no cuidado aos contratantes dos planos de saúde, verificando a gestão da receita e despesa de recursos financeiros (ANS, 2016).

No que tange à administração das operadoras e do sistema, é necessário ressaltar a gestão em saúde, pois embora seja tratada como mercadoria, as demandas que este setor exige são diferentes. O surgimento dos sistemas de saúde, resultou no desenvolvimento de uma cultura sanitária que organizasse os serviços e programas seguindo uma nova linha de administração.

\section{O Sistema Integrado de Saúde}

O Sistema Integrado de Saúde (SIS), é um sistema de autogestão que coordena os serviços do plano de saúde conveniado à um Órgão Público Federal, de forma a proporcionar aos servidores ativos e inativos, bem como aos seus dependentes, assistência com vistas à prevenção de doenças, e à promoção, tratamento, recuperação e manutenção da saúde (Brasil, 2012b).

Para oferta do serviço, instituições devem ser credenciadas junto ao sistema, podendo as mesmas serem públicas ou privadas. O credenciamento se dá através da excelência profissional, existência de instalações adequadas, habilitação técnica requerida pela especialidade e garantia da concessão do mesmo padrão de atendimento dispensado aos clientes particulares (Brasil, 2012b). 
Artigo de Revisão

Hegemonia - Revista Eletrônica do Programa de Mestrado em Direitos Humanos, Cidadania e Violência/Ciência Política do Centro Universitário Unieuro

ISSN: $1809-1261$

UNIEURO, Brasília, número 27 (Especial), 2019, pp. 128-160.

Além do credenciamento citado anteriormente, também há disponível na regulamentação do sistema, rol de procedimentos que são cobertos pelo plano, e também os que não são, a exemplo, estadia em clínicas de repouso (Brasil, 2012b).

O financiamento deste plano de autogestão, ocorre através de recursos da União, alocados através da lei orçamentária anual e do Fundo de Reserva do SIS. Este fundo é formado através da contribuição mensal dos beneficiários, receitas de aplicações financeiras, taxas e multas cobradas dos beneficiários, doações e transferências recebidas (Brasil, 2012b).

\section{METODOLOGIA}

Trata-se de um estudo quantitativo descritivo exploratório, que analisou o plano de autogestão de um serviço público federal, utilizado por funcionários da instituição e seus respectivos dependentes.

Foram utilizados relatórios da empresa responsável pelas auditorias do plano de saúde, para o levantamento dos dados de internações e custos; o relatório disponibilizado pela Rede Unidas no período de 2016, para o levantamento das internações dos usuários dos planos de saúde que são caracterizados como autogestão. Foram também utilizados dados disponibilizados no Sistema de Informação do SUS para internações hospitalares (AIH) para compor as condições de internações no Distrito Federal no ano de 2016.

A população do estudo foram os segurados que estavam cadastrados na plataforma e a amostra utilizada foram dos usuários que utilizaram do plano no ano de 2016. O período estudado compreendeu os meses de fevereiro a dezembro do respectivo ano, pois os dados de janeiro estavam indisponíveis.

Os dados foram disponibilizados pela operadora de autogestão responsável pela administração do Plano de Saúde. Utilizou-se das seguintes variáveis: capítulo do CID 10, número de dias de internação, número total de internações e custo total da internação para os dois sistemas de saúde (autogestão e SUS).

Foram acrescentadas as variáveis de custo médio de internação e da média de diárias por internações. Embora a operadora do plano de saúde tenha cobertura em todo o território nacional, 
Artigo de Revisão

Hegemonia - Revista Eletrônica do Programa de Mestrado em Direitos Humanos, Cidadania e Violência/Ciência Política do Centro Universitário Unieuro

ISSN: $1809-1261$

UNIEURO, Brasília, número 27 (Especial), 2019, pp. 128-160.

os dados utilizados são referentes às internações e atendimentos em Brasília. Com isso, a comparação ocorreu com dados referentes ao Distrito Federal.

Os dados utilizados na pesquisa foram recebidos em formato pdf, cada mês do ano de 2016. Foram elegidos para a pesquisa o relatório nosológico, onde estavam descritos o CID, admissões no mês de referência, altas, faturas auditadas, diárias, internações, custo total da patologia, custo médio por internação, custo médio por dia de internação e tempo médio de permanência.

Para realização da análise, os dados foram convertidos em planilha do Microsoft Excel ${ }^{\circledR}$ e salvos no formato csv, para posteriormente serem manipulados através do Software R ${ }^{\circledR}$.

No Software R, a planilha foi importada através de comandos, e foi instalado o pacote dplyr, pacote disponibilizado no site do software, que permite o agrupamento e soma dos dados, posteriormente os transformando em tabela.

Os dados foram depois exportados para o Microsoft Excel ${ }^{\circledR}$ para confecção das tabelas.

Por se tratar de uma análise documental, não houve necessidade de submissão ao Comitê de Ética em Pesquisa, segundo a Resolução 466 de dezembro de 2012 da Comissão Nacional de Ética em Pesquisa (CONEP). Entretanto, a pesquisa foi autorizada pela instituição administradora do Plano de Saúde, através da assinatura do Termo de Anuência de Coparticipação e Termo de Responsabilidade e Compromisso do Pesquisador Responsável.

\section{RESULTADOS E DISCUSSÃO}

A rede de planos de autogestão, é gerida pela Rede Unidas, onde alguns dados como o perfil dos beneficiários, tipo de procedimentos e custos, são enviados pela operadora à associação. De tal forma, no relatório emitido pela Unidas no ano de 2016, revela o perfil do beneficiário da autogestão.

No perfil elaborado, 54,4\% dos beneficiários, são do sexo feminino, e 46,6\% do sexo masculino. No que diz respeito à faixa etária, 30\% da população assistida pelo plano de saúde, corresponde a 59 anos ou mais. Grande parte das operadoras filiadas à Unidas, possuem cerca de $20 \%$ da população idosa. 
Artigo de Revisão

Hegemonia - Revista Eletrônica do Programa de Mestrado em Direitos Humanos, Cidadania e Violência/Ciência Política do Centro Universitário Unieuro

ISSN: $1809-1261$

UNIEURO, Brasília, número 27 (Especial), 2019, pp. 128-160.

Para análise dos dados, foram elencadas as informações de internações referentes ao sistema de autogestão, e em seguida as informações do SUS, no ano de 2016. As causas de internações - capítulos CID-10 - expressam o comportamento da população, sendo possível inferir, através das mesmas, a condição de saúde do beneficiário no que se refere à morbidade.

A Tabela 1 apresenta os dados do sistema na modalidade de autogestão; na distribuição por custo dos procedimentos, o grupo CID-10 que apresentou maior custo para o plano de saúde, foi o Capítulo IX - Doenças do aparelho circulatório, destacando-se também, quanto ao número total de internações (404 no período).

O grupo do Capítulo IX, contabilizou mais de 11 milhões de reais com as internações, ao custo médio de 29.400,73 reais. Em contrapartida, o grupo com menor custo, foi o grupo VIII Doenças do ouvido e da apófise mastóide, com o custo médio de $\mathrm{R} \$ 6.377,73$, o total de 5 internações, tendo média de 2,20 dias de internação. Embora apresente o menor custo, este capítulo não apresenta a menor média diárias por internações $(2,20)$, ficando este dado para o capítulo VII - Doenças do olho e anexos (com média de 0,50 diárias por internações). 
Artigo de Revisão

Hegemonia - Revista Eletrônica do Programa de Mestrado em Direitos Humanos, Cidadania e Violência/Ciência Política do Centro Universitário Unieuro

ISSN: 1809-1261

UNIEURO, Brasília, número 27 (Especial), 2019, pp. 128-160.

Tabela 1 - Distribuição da frequência das internações e custos hospitalares do plano de autogestão no ano de 2016. Brasília, 2017.

\begin{tabular}{|c|c|c|c|c|c|c|}
\hline $\mathrm{N}^{\circ}$ & CAPÍTULO CID-10 & $\begin{array}{l}\mathrm{N}^{\circ} \text { TOTAL } \\
\text { DE } \\
\text { DIARIAS }\end{array}$ & $\begin{array}{c}\text { CUSTO TOTAL } \\
\text { DE } \\
\text { INTERNAÇÕES }\end{array}$ & $\begin{array}{l}\mathrm{N}^{\circ} \text { TOTAL DE } \\
\text { INTERNAÇÕES }\end{array}$ & $\begin{array}{c}\text { CUSTO MÉDIO } \\
\text { DE } \\
\text { INTERNAÇÃO }\end{array}$ & $\begin{array}{l}\text { MÉDIA DE } \\
\text { DIÁRIAS POR } \\
\text { INTERNAÇÃO }\end{array}$ \\
\hline 1 & $\begin{array}{l}\text { IX - DOENÇAS DO } \\
\text { APARELHO } \\
\text { CIRCULATÓRIO }\end{array}$ & 2009 & $\mathrm{R} \$ 11.877 .894,45$ & 404 & $\mathrm{R} \$ 29.400,73$ & 4,97 \\
\hline 2 & $\begin{array}{l}\text { X - DOENÇAS DO } \\
\text { APARELHO } \\
\text { RESPIRATÓRIO }\end{array}$ & 940 & $\mathrm{R} \$ 4.572 .067,76$ & 165 & $\mathrm{R} \$ 27.709,50$ & 5,70 \\
\hline 3 & $\begin{array}{l}\text { XXI - FATORES QUE } \\
\text { INFLUENCIAM O } \\
\text { ESTADO DE SAÚDE E } \\
\text { O CONTATO COM OS } \\
\text { SERVIÇOS DE SAÚDE }\end{array}$ & 681 & $\mathrm{R} \$ 4.285 .904,03$ & 344 & $\mathrm{R} \$ 12.459,02$ & 1,98 \\
\hline 4 & $\begin{array}{l}\text { XIV - DOENÇAS DO } \\
\text { APARELHO } \\
\text { GENITURINÁRIO }\end{array}$ & 919 & $\mathrm{R} \$ 3.981 .783,79$ & 250 & $\mathrm{R} \$ 15.927,14$ & 3,68 \\
\hline 5 & $\begin{array}{l}\text { II - NEOPLASIAS } \\
\text { [TUMORES] }\end{array}$ & 374 & $\mathrm{R} \$ 3.375 .470,44$ & 222 & $\mathrm{R} \$ 15.204,82$ & 1,68 \\
\hline 6 & $\begin{array}{l}\text { XI - DOENÇAS DO } \\
\text { APARELHO } \\
\text { DIGESTIVO }\end{array}$ & 444 & $\mathrm{R} \$ 2.441 .847,24$ & 144 & $\mathrm{R} \$ 16.957,27$ & 3,08 \\
\hline 7 & $\begin{array}{l}\text { XIII - DOENÇAS DO } \\
\text { SISTEMA } \\
\text { OSTEOMUSCULAR E } \\
\text { DO TECIDO } \\
\text { CONJUNTIVO }\end{array}$ & 234 & $\mathrm{R} \$ 2.420 .919,43$ & 85 & $\mathrm{R} \$ 28.481,41$ & 2,75 \\
\hline 8 & $\begin{array}{l}\text { XVIII - SINTOMAS, } \\
\text { SINAIS E ACHADOS } \\
\text { ANORMAIS DE } \\
\text { EXAMES CLÍNICOS E } \\
\text { DE LABORATÓRIO, } \\
\text { NÃO CLASSIFICADOS } \\
\text { EM OUTRA PARTE }\end{array}$ & 576 & $\mathrm{R} \$ 2.306 .537,66$ & 136 & $\mathrm{R} \$ 16.959,84$ & 4,24 \\
\hline 9 & $\begin{array}{l}\text { XIX - LESÕES, } \\
\text { ENVENENAMENTOS } \\
\text { E ALGUMAS OUTRAS } \\
\text { CONSEQUENCIAS DE } \\
\text { CAUSAS EXTERNAS E } \\
\text { XX - CAUSAS } \\
\text { EXTERNAS DE } \\
\text { MORBIDADE E DE } \\
\text { MORTALIDADE }\end{array}$ & 273 & $\mathrm{R} \$ 2.165 .521,09$ & 74 & $\mathrm{R} \$ 29.263,80$ & 3,69 \\
\hline 10 & $\begin{array}{l}\text { I - ALGUMAS } \\
\text { DOENÇAS } \\
\text { INFECCIOSAS E } \\
\text { PARASITÁRIAS }\end{array}$ & 343 & $\mathrm{R} \$ 1.476 .735,48$ & 61 & $\mathrm{R} \$ 24.208,78$ & 5,62 \\
\hline 11 & $\begin{array}{l}\text { VI - DOENÇAS DO } \\
\text { SISTEMA NERVOSO }\end{array}$ & 246 & $\mathrm{R} \$ 1.451 .722,73$ & 37 & $\mathrm{R} \$ 39.235,75$ & 6,65 \\
\hline 12 & $\begin{array}{l}\text { IV - DOENÇAS } \\
\text { ENDÓCRINAS, } \\
\text { NUTRICIONAIS E } \\
\text { METABÓLICAS }\end{array}$ & 285 & $\mathrm{R} \$ 1.033 .677,18$ & 31 & $\mathrm{R} \$ 33.344,43$ & 9,19 \\
\hline 13 & $\begin{array}{l}\text { XII - DOENÇAS DA } \\
\text { PELE E DO TECIDO } \\
\text { CELULAR } \\
\text { SUBCUTÂNEO }\end{array}$ & 149 & $\mathrm{R} \$ 858.282,80$ & 18 & $\mathrm{R} \$ 47.682,38$ & 8,28 \\
\hline 14 & XV - GRAVIDEZ, & 93 & $\mathrm{R} \$ 323.133,50$ & 48 & $\mathrm{R} \$ 6.731,95$ & 1,94 \\
\hline
\end{tabular}


Artigo de Revisão

Hegemonia - Revista Eletrônica do Programa de Mestrado em Direitos Humanos, Cidadania e Violência/Ciência Política do Centro Universitário Unieuro

ISSN: 1809-1261

UNIEURO, Brasília, número 27 (Especial), 2019, pp. 128-160.

\begin{tabular}{|c|c|c|c|c|c|c|}
\hline & PARTO E PUERPÉRIO & & & & & \\
\hline 15 & $\begin{array}{l}\text { V - TRANSTORNOS } \\
\text { MENTAIS E } \\
\text { COMPORTAMENTAIS }\end{array}$ & 71 & $\mathrm{R} \$ 242.557,67$ & 7 & $\mathrm{R} \$ 34.651,10$ & 10,14 \\
\hline 16 & $\begin{array}{l}\text { XVI - ALGUMAS } \\
\text { AFECÇÕES } \\
\text { ORIGINADAS NO } \\
\text { PERÍODO } \\
\text { PERINATAL }\end{array}$ & 95 & $\mathrm{R} \$ 222.051,83$ & 17 & $\mathrm{R} \$ 13.061,87$ & 5,59 \\
\hline 17 & $\begin{array}{l}\text { III - DOENÇAS DO } \\
\text { SANGUE E DOS } \\
\text { ÓRGÃOS } \\
\text { HEMATOPOÉTICOS E } \\
\text { ALGUNS } \\
\text { TRANSTORNOS } \\
\text { IMUNITÁRIOS }\end{array}$ & 20 & $\mathrm{R} \$ 89.709,87$ & 8 & $\mathrm{R} \$ 11.213,73$ & 2,50 \\
\hline 18 & $\begin{array}{l}\text { VII - DOENÇAS DO } \\
\text { OLHO E ANEXOS }\end{array}$ & 2 & $\mathrm{R} \$ 36.016,29$ & 4 & $\mathrm{R} \$ 9.004,07$ & 0,50 \\
\hline 19 & $\begin{array}{l}\text { VIII - DOENÇAS DO } \\
\text { OUVIDO E DA } \\
\text { APÓFISE MASTÓIDE }\end{array}$ & 11 & $\mathrm{R} \$ 31.888,65$ & 5 & $\mathrm{R} \$ 6.377,73$ & 2,20 \\
\hline
\end{tabular}

Fonte: Relatórios de auditoria do plano de autogestão. 2016.

Segundo Vieira et al (2016), as doenças do aparelho circulatório, são consequência da urbanização e da industrialização. Além desse fator, a transição demográfica também tem sua parcela de influência, visto o envelhecimento da população. Outro fator de risco relevante, é que a população com faixa etária maior de 40 anos, é mais suscetível a ter sequelas, após acidentes com as DAC.

As doenças do aparelho respiratório (Capítulo X), aparecem em segundo lugar, com maior custo de internações (mais de 4 milhões de reais no período). Tal fator pode ser influenciado pelas condições climáticas do estado, que propiciam a doenças e agravos respiratórios. Em estudo realizado por Oliveira (2014), na cidade de Montes Claros (MG), verificou-se que no período que há redução da temperatura e da umidade - clima predominante no DF -, tem-se aumento das internações por causas respiratórias, principalmente pneumonia (soma mais de 45\% das internações totais).

Silveira et al (2013), fala sobre os principais gastos com hospitalização de idosos no Brasil nos anos de 2002 a 2011, e consequentemente, o número de internações. Quando analisado esse dado, junto às internações do plano de saúde, percebe-se que esse comportamento dos usuários não é exclusivo aos beneficiários. No que tange à idade, verifica-se que o padrão descrito é comum aos usuários com idade superior a 60 anos. No estudo de Silveira et al (2013), foram internados 
Artigo de Revisão

Hegemonia - Revista Eletrônica do Programa de Mestrado em Direitos Humanos, Cidadania e Violência/Ciência Política do Centro Universitário Unieuro

ISSN: $1809-1261$

UNIEURO, Brasília, número 27 (Especial), 2019, pp. 128-160.

27\% a mais de idosos (60 anos ou mais) por Doenças do Aparelho Circulatório, que jovens (20 a 59 anos).

Segundo a Unidas (2016), a maior parte dos beneficiários titulares do plano de saúde $(35,5 \%)$ corresponde à faixa etária de 59 anos ou mais. No que tange aos dependentes, o padrão continua o mesmo, com 30,6\% dos beneficiários desta faixa etária. Apenas os agregados - pessoas com terceiro grau de parentesco consanguíneo ou afim - ao plano de saúde, os usuários com até 18 anos têm predominância (18,5\%), e os usuários de 59 anos ou mais $(17,5 \%)$.

Embora os dados que Silveira et al (2013) discorram sejam anteriores ao período estudado, é perceptível que a mudança do perfil demográfico do usuário brasileiro está ocorrendo há certo tempo e se solidificando, mostrando também a necessidade dos sistemas de atendimento se adaptarem a ele.

O Capítulo XXI do CID-10, Fatores que influenciam o estado de saúde e o contato com os serviços de saúde, obteve custo de mais de 4 milhões para o sistema de autogestão, mesmo com o número de internações inferior (681 internações) ao item subsequente, Capítulo XIV - Doenças do aparelho geniturinário (com 919 internações). Cabe destacar que para esse item, a média de diárias de internações foi de 1,98 dia.

O Capítulo XXI, é utilizado quando a causa de internação não é uma doença, traumatismo ou uma causa externa, a causa pode ser registrada como diagnóstico ou problema. Pode ocorrer quando a pessoa consulta os serviços de saúde para receber assistência ou serviço limitado, como por exemplo receber imunização profilática, ou discutir uma doença (OMS, 1997).

Em quarto lugar, nas causas de internações dos beneficiários da operadora de autogestão, encontra-se o Capítulo XIV - doenças do aparelho geniturinário, com custos que quase chegam a 4 milhões de reais pelas internações no período, e com o total de apenas 250 internações, ou seja, alto custo de internação, determinado pela prolongação da mesma.

Góis e Veras (2010), compararam as causas de internações em idosos no SUS nos anos de 1994 e 2005, e perceberam que as internações pelo Capítulo XIV não tiveram redução significável, e atribuíram esta internação à fragilidade do idoso, e também a propensão de infecções hospitalares do idoso já internado por outro motivo. Pode-se também inferir que tais internações sejam típicas do avanço da idade, como as doenças relacionadas à próstata. 
Artigo de Revisão

Hegemonia - Revista Eletrônica do Programa de Mestrado em Direitos Humanos, Cidadania e Violência/Ciência Política do Centro Universitário Unieuro

ISSN: $1809-1261$

UNIEURO, Brasília, número 27 (Especial), 2019, pp. 128-160.

O Capítulo II - neoplasias [tumores], aparece em quinto lugar com maior custo para o sistema de autogestão - mais de três milhões e trezentos mil reais - entretanto, fica em quarto lugar, quando se trata do total de internações (222) no período. Para Pilger et al (2011) a maior ocorrência de neoplasias, é em idosos, e se dá pelo tempo de exposição ao agente causador, que acontece ao longo da vida do indivíduo.

No sistema de autogestão, a gravidez, parto e puerpério (Capítulo XV), aparece em décimo quinto lugar, podendo inferir-se que, como apresentado anteriormente, que a população atendida pelo sistema, tem, em sua maior parte 59 anos ou mais, ou seja, esta população não está em idade reprodutiva, reduzindo a quantidade de internações por este motivo.

O relatório emitido pela Unidas, no tópico que trata das causas das internações, revela um padrão similar ao adotado pela operadora de saúde estudada. Destacam-se as internações por DAC, com $12,7 \%$ das internações. Em seguida, os capítulos CID-10 com as maiores porcentagens de internação são os Capítulos XVIII - Sintomas, sinais e achados anormais de exames clínicos e de laboratório, não classificados em outra parte (10,6\% das internações) e o Capítulo XIV - Doenças do aparelho geniturinário, com 10,1\%. Caracterizando a população idosa.

Ante o exposto, infere-se que os capítulos do CID-10 que têm predominância nas causas de internação, são por agravos à saúde em pessoas com idade avançada. De tal forma, observa-se que o perfil demográfico dos usuários dos planos de saúde tem predominância de idosos, ou seja, a realidade do sistema de saúde de autogestão, é para tratar e atender, em sua maioria, pessoas com idade avançada, sendo um retrato diferente da população atendida pelo SUS.

Segundo o CONASS (2006), 28,6\% dos brasileiros eram usuários exclusivos do SUS, 61,5\% eram usuários não exclusivos do sistema e apenas 8,7\% não usuários. Ou seja, $61,5 \%$ dos brasileiros que utilizavam o SUS, possuíam também atendimento privado, através de convênios de saúde.

No censo demográfico realizado pelo IBGE em 2010, a população do Distrito Federal era de 2.570 .160 de pessoas. Destes, $51 \%$ eram mulheres e $49 \%$ homens. Destas mulheres, 32,4\% estava em idade fértil - mulheres de 10 a 49 anos.

No que se refere a situação das informações do Sistema Único de Saúde no Distrito Federal, a tabela 2 trará a distribuição das frequências das internações e custos nos serviços 
Artigo de Revisão

Hegemonia - Revista Eletrônica do Programa de Mestrado em Direitos Humanos, Cidadania e Violência/Ciência Política do Centro Universitário Unieuro

ISSN: $1809-1261$

UNIEURO, Brasília, número 27 (Especial), 2019, pp. 128-160.

hospitalares no Distrito Federal.

Tabela 2 - Distribuição da frequência das internações e custos das internações hospitalares no SUS, no Distrito Federal, no ano de 2016. Brasília, 2017.

\begin{tabular}{|c|c|c|c|c|c|c|}
\hline $\mathrm{N}^{\circ}$ & CAPÍTULO CID-10 & $\begin{array}{l}\text { No TOTAL } \\
\text { DE } \\
\text { DIARIAS }\end{array}$ & $\begin{array}{l}\text { CUSTO TOTAL } \\
\text { DE } \\
\text { INTERNAÇÕES }\end{array}$ & $\begin{array}{l}\text { No TOTAL DE } \\
\text { INTERNAÇÕES }\end{array}$ & $\begin{array}{l}\text { CUSTO MÉDIO } \\
\text { DE } \\
\text { INTERNAÇÃO }\end{array}$ & $\begin{array}{l}\text { MÉDIA DE } \\
\text { DIÁRIAS POR } \\
\text { INTERNAÇÃO }\end{array}$ \\
\hline 1 & $\begin{array}{l}\text { IX - DOENÇAS DO } \\
\text { APARELHO } \\
\text { CIRCULATÓRIO }\end{array}$ & 132684 & $\mathrm{R} \$ 33.847 .395,04$ & 14055 & $\mathrm{R} \$ 2.408,21$ & 9,44 \\
\hline 2 & $\begin{array}{l}\text { XV - GRAVIDEZ, PARTO } \\
\text { E PUERPERIO }\end{array}$ & 151461 & $\mathrm{R} \$ 26.948 .839,65$ & 45611 & $\mathrm{R} \$ 590,84$ & 3,32 \\
\hline 3 & $\begin{array}{l}\text { XIX - LESÕES, } \\
\text { ENVENENAMENTOS E } \\
\text { ALGUMAS OUTRAS } \\
\text { CONSEQUENCIAS DE } \\
\text { CAUSAS EXTERNAS }\end{array}$ & 133999 & $\mathrm{R} \$ 19.180 .072,92$ & 16890 & $\mathrm{R} \$ 1.135,59$ & 7,93 \\
\hline 4 & $\begin{array}{l}\text { II - NEOPLASIAS } \\
\text { [TUMORES }\end{array}$ & 79582 & $\mathrm{R} \$ 15.336 .676,56$ & 10074 & $\mathrm{R} \$ 1.522,40$ & 7,90 \\
\hline 5 & $\begin{array}{l}\text { X-DOENÇAS DO } \\
\text { APARELHO } \\
\text { RESPIRATÓRIO }\end{array}$ & 99465 & $\mathrm{R} \$ 15.097 .236,95$ & 13017 & $\mathrm{R} \$ 1.159,81$ & 7,64 \\
\hline 6 & $\begin{array}{l}\text { XI - DOENÇAS DO } \\
\text { APARELHO DIGESTIVO }\end{array}$ & 75014 & $\mathrm{R} \$ 14.348 .797,75$ & 13202 & $\mathrm{R} \$ 1.086,87$ & 5,68 \\
\hline 7 & $\begin{array}{l}\text { XVI - ALGUMAS } \\
\text { AFECÇÕES } \\
\text { ORIGINADAS NO } \\
\text { PERÍODO PERINATAL }\end{array}$ & 76409 & $\mathrm{R} \$ 11.369 .344,81$ & 10134 & $\mathrm{R} \$ 1.121,90$ & 7,54 \\
\hline 8 & $\begin{array}{l}\text { I - ALGUMAS DOENÇAS } \\
\text { INFECCIOSAS E } \\
\text { PARASITÁRIAS }\end{array}$ & 69407 & $\mathrm{R} \$ 10.405 .670,08$ & 7412 & $\mathrm{R} \$ 1.403,90$ & 9,36 \\
\hline 9 & $\begin{array}{l}\text { XIV - DOENÇAS DO } \\
\text { APARELHO } \\
\text { GENITURINÁRIO }\end{array}$ & 60828 & $\mathrm{R} \$ 8.307 .230,80$ & 10072 & $\mathrm{R} \$ 824,78$ & 6,04 \\
\hline 10 & $\begin{array}{l}\text { XVII - MALFORMAÇÕES } \\
\text { CONGÊNITAS, } \\
\text { DEFORMIDASE } \\
\text { ANOMALIAS } \\
\text { CROMOSSÔMICAS }\end{array}$ & 16668 & $\mathrm{R} \$ 6.903 .966,23$ & 2124 & $\mathrm{R} \$ 3.250,45$ & 7,85 \\
\hline 11 & $\begin{array}{l}\text { XIII - DOENÇAS DO } \\
\text { SISTEMA } \\
\text { OSTEOMUSCULAR E } \\
\text { DO TECIDO } \\
\text { CONJUNTIVO }\end{array}$ & 30707 & $\mathrm{R} \$ 6.457 .185,23$ & 4077 & $\mathrm{R} \$ 1.583,81$ & 7,53 \\
\hline 12 & $\begin{array}{l}\text { VI - DOENÇAS DO } \\
\text { SISTEMA NERVOSO }\end{array}$ & 51813 & $\mathrm{R} \$ 5.522 .080,02$ & 5274 & $\mathrm{R} \$ 1.047,04$ & 9,82 \\
\hline 13 & $\begin{array}{l}\text { XVIII - SINTOMAS, } \\
\text { SINAIS E ACHADOS } \\
\text { ANORMAIS DE EXAMES } \\
\text { CLÍNICOS E DE } \\
\text { LABORATÓRIO, NÃO } \\
\text { CLASSIFICADOS EM } \\
\text { OUTRA PARTE }\end{array}$ & 22185 & $\mathrm{R} \$ 2.656 .202,55$ & 5735 & $\mathrm{R} \$ 463,16$ & 3,87 \\
\hline 14 & $\begin{array}{l}\text { XXI - FATORES QUE } \\
\text { INFLUENCIAM O } \\
\text { ESTADO DE SAÚDE E O } \\
\text { CONTATO COM OS }\end{array}$ & 7303 & $\mathrm{R} \$ 1.974 .964,40$ & 2674 & $\mathrm{R} \$ 738,58$ & 2,73 \\
\hline
\end{tabular}


Artigo de Revisão

Hegemonia - Revista Eletrônica do Programa de Mestrado em Direitos Humanos, Cidadania e Violência/Ciência Política do Centro Universitário Unieuro

ISSN: 1809-1261

UNIEURO, Brasília, número 27 (Especial), 2019, pp. 128-160.

\begin{tabular}{|c|c|c|c|c|c|c|}
\hline & SERVIÇOS DE SAÚDE & & & & & \\
\hline 15 & $\begin{array}{l}\text { IV - DOENÇAS } \\
\text { ENDÓCRINAS, } \\
\text { NUTRICIONAIS E } \\
\text { METABÓLICAS }\end{array}$ & 22027 & $\mathrm{R} \$ 1.718 .150,94$ & 2371 & $R \$ 724,65$ & 9,29 \\
\hline 16 & $\begin{array}{l}\text { V - TRANSTORNOS } \\
\text { MENTAIS E } \\
\text { COMPORTAMENTAIS }\end{array}$ & 37944 & $\mathrm{R} \$ 1.717 .923,75$ & 3796 & $\mathrm{R} \$ 452,56$ & 10,00 \\
\hline 17 & $\begin{array}{l}\text { VII - DOENÇAS DO } \\
\text { OLHO E ANEXOS }\end{array}$ & 1828 & $\mathrm{R} \$ 1.384 .930,86$ & 1798 & $\mathrm{R} \$ 770,26$ & 1,02 \\
\hline 18 & $\begin{array}{l}\text { XII - DOENÇAS DA } \\
\text { PELE E DO TECIDO } \\
\text { CELULAR } \\
\text { SUBCUTÂNEO }\end{array}$ & 17983 & $\mathrm{R} \$ 1.225 .376,29$ & 2671 & $\mathrm{R} \$ 458,77$ & 6,73 \\
\hline 19 & $\begin{array}{l}\text { III - DOENÇAS DO } \\
\text { SANGUE DOS } \\
\text { ÓRGÃOS } \\
\text { HEMATOPOÉTICOS E } \\
\text { ALGUNS } \\
\text { TRANSTORNOS } \\
\text { IMUNITÁRIOS }\end{array}$ & 9364 & $\mathrm{R} \$ 861.214,34$ & 1755 & $\mathrm{R} \$ 490,72$ & 5,34 \\
\hline 20 & $\begin{array}{l}\text { VIII - DOENÇAS DO } \\
\text { OUVIDO E DA APÓFISE } \\
\text { MASTÓIDE }\end{array}$ & 1178 & $\mathrm{R} \$ 759.886,16$ & 333 & $\mathrm{R} \$ 2.281,94$ & 3,54 \\
\hline
\end{tabular}

Fonte: Datasus, 2017.

As doenças do aparelho circulatório apareceram em primeiro lugar nas causas de internações no SUS no Distrito Federal. Destaca-se que ela apresenta duas vezes mais, o tempo médio de internação do paciente no plano de autogestão. $\mathrm{O}$ mesmo se dá pelo baixo valor da internação com custo médio 12 vezes menor que na autogestão.

As doenças com maior incidência, se assemelham às doenças identificadas no plano de saúde e também no estudo realizado por Silveira et al (2013), reforçando o perfil epidemiológico da população. Marques e Confortin (2015), também identificaram prevalência de doenças do aparelho circulatório, como principal causa de internação entre idosos.

A melhora no comportamento do brasileiro em relação à hábitos alimentares, e no implemento de atividades físicas na rotina, como mostrado no Vigitel 2016, deveria refletir nas internações, principalmente nas DAC, pois para a Abeso (2009), os principais fatores que influenciam a obesidade na população, são a diminuição de atividade física e a alta ingestão calórica de alimentos.

No SUS, em segundo lugar na distribuição por custos, aparece o Capítulo XV - gravidez, parto e puerpério, todavia, o mesmo é a maior causa de internações no Distrito Federal, no ano de 2016. A média de diárias por internações, corresponde à uma das menores encontradas no estudo (3,32 dias). A despesa também é uma das mais baixos para o sistema de saúde, com média de 590,84 
Artigo de Revisão

Hegemonia - Revista Eletrônica do Programa de Mestrado em Direitos Humanos, Cidadania e Violência/Ciência Política do Centro Universitário Unieuro

ISSN: 1809-1261

UNIEURO, Brasília, número 27 (Especial), 2019, pp. 128-160.

reais por internação.

O sistema de saúde de autogestão, tem comportamento diferente do SUS, onde, mesmo com beneficiários com idade não propensa a engravidar, os custos dos procedimentos são alarmantes, com média de mais se seis mil reais por internação, onze vezes mais cara que a internação no SUS. A média de diárias é outro fator que se destaca, onde há permanência da gestante por apenas 1,94 dia no hospital, reforçando a prevalência de partos cesáreos nesse sistema.

Foi observado que cerca de um quarto das internações realizadas no SUS, em todo o país no período de 1995 a 2005, refere-se ao Capítulo XV, mesmo com redução da taxa de fecundidade no país (RIPSA, 2010).

Os Capítulos XIX - Lesões, envenenamentos e algumas outras consequências de causas externas e o Capítulo XX - Causas externas de morbidade e de mortalidade, compõe o terceiro maior custo para o Sistema Único de Saúde. Na internação desses pacientes, o diagnóstico principal, se dá pelo tipo de traumatismo (Capítulo XIX) e posteriormente, seu prontuário pode ser alterado, informando o que causou o traumatismo (Capítulo XX) (Brasil, 2008). De tal forma, os dados encontrados, dispunham dos dois capítulos já unificados, fazendo com que os capítulos do sistema de autogestão também fossem unidos, para comparação adequada.

Os usuários que são internados por esta causa no SUS, têm uma média alta de diárias por internação (7,93 dias) e apresenta o custo total de quase 20 milhões de reais por ano. Na autogestão, o beneficiário internado por este Capítulo CID-10, tem permanência menor, com média de 3,69 dias, e o custo médio das internações é de 29.263,80 reais, ou seja, quase trinta vezes mais que a internação no SUS.

Jorge, Koizumi e Tono (2007) dizem que as internações por causas externas e outras consequências, são mais onerosas aos cofres públicos que as internações relativas às causas naturais, e o paciente permanece por muito tempo no hospital, informação notada neste estudo.

As neoplasias, custaram no ano de 2016, mais de 15 milhões de reais ao SUS, tendo uma média de 7,90 dias por internação. Boino, Vargas e Boino (2007), analisaram a morbidade e a mortalidade no SUS nos anos de 2002 a 2004, e observaram que as internações por leucemia, apresentaram maior valor médio por internação e maior gasto total. As internações por tumores benignos, tem gasto médio baixo, porém, com grande volume de internações. Outro fator notado 
Artigo de Revisão

Hegemonia - Revista Eletrônica do Programa de Mestrado em Direitos Humanos, Cidadania e Violência/Ciência Política do Centro Universitário Unieuro

ISSN: 1809-1261

UNIEURO, Brasília, número 27 (Especial), 2019, pp. 128-160.

pelos autores, é que a taxa de mortalidade por neoplasias é maior no sexo masculino.

$\mathrm{Na}$ sequência das internações de maior custo, aparece o Capítulo X - Doenças do aparelho respiratório, com quinze milhões de reais gastos no período. A média de diária por internação no SUS, foi de 7,64 dias. No sistema de autogestão, este fator aparece em segundo lugar, entretanto, a média de diária foi menor, com 5,70 dias por internação. Na autogestão, gastou-se menos, quando comparado com o total do SUS, mas a média do valor por internação, retrata que o custo dessa internação para a autogestão é vinte e três vezes maior.

É perceptível que as internações no SUS têm tempo de permanência maior que na autogestão, entretanto as condições oferecidas aos usuários de cada sistema, é diferente. No Sistema Único de Saúde, há recorrentes reclamações de falta de insumos e leitos, que viabilizem o cuidado em tempo adequado. No sistema de autogestão, por haver contribuição do beneficiário, e também haver a rede credenciada - privada - que assistirá o paciente, a falta de insumos não ocorre, ou ocorre de modo que não prejudica o atendimento.

Para comparar as internações e os custos de cada sistema, de maneira mais eficaz, na Tabela 3 pode-se verificar a média de internações e custos de cada sistema de saúde.

Tabela 3 - Custos médios de internação e médias de diárias por internações, na operadora de autogestão e no Sistema Único de Saúde do Distrito Federal. Brasília, 2016.

\begin{tabular}{|c|c|c|c|c|}
\hline \multirow[b]{2}{*}{ CAPÍTULO CID-10 } & \multicolumn{2}{|c|}{ OPERADORA } & \multicolumn{2}{|c|}{ SUS } \\
\hline & $\begin{array}{l}\text { CUSTO MÉDIO DE } \\
\text { INTERNAÇÃO }\end{array}$ & $\begin{array}{l}\text { MÉDIA DE DIÁRIAS } \\
\text { POR INTERNAÇÃO }\end{array}$ & $\begin{array}{l}\text { CUSTO MÉDIO DE } \\
\text { INTERNAÇÃO }\end{array}$ & $\begin{array}{l}\text { MÉDIA DE DIÁRIAS } \\
\text { POR INTERNAÇÃO }\end{array}$ \\
\hline $\begin{array}{l}\text { I - ALGUMAS DOENÇAS } \\
\text { INFECCIOSAS E PARASITÁRIAS }\end{array}$ & $\mathrm{R} \$ 24.208,78$ & 5,62 & $\mathrm{R} \$ 1.403,90$ & 9,36 \\
\hline II - NEOPLASIAS [TUMORES] & $\mathrm{R} \$ 15.204,82$ & 1,68 & $\mathrm{R} \$ 1.522,40$ & 7,90 \\
\hline $\begin{array}{l}\text { III - DOENÇAS DO SANGUE E } \\
\text { DOS ÓRGÃOS } \\
\text { HEMATOPOÉTICOS E ALGUNS } \\
\text { TRANSTORNOS IMUNITÁRIOS }\end{array}$ & $\mathrm{R} \$ 11.213,73$ & 2,50 & $\mathrm{R} \$ \quad 490,72$ & 5,34 \\
\hline $\begin{array}{l}\text { IV - DOENÇAS ENDÓCRINAS, } \\
\text { NUTRICIONAIS E METABÓLICAS }\end{array}$ & $\mathrm{R} \$ 33.344,43$ & 9,19 & $\mathrm{R} \$ \quad 724,65$ & 9,29 \\
\hline $\begin{array}{l}\text { V - TRANSTORNOS MENTAIS E } \\
\text { COMPORTAMENTAIS }\end{array}$ & $\mathrm{R} \$ 34.651,10$ & 10,14 & $\mathrm{R} \$ \quad 452,56$ & 10,00 \\
\hline $\begin{array}{l}\text { VI - DOENÇAS DO SISTEMA } \\
\text { NERVOSO }\end{array}$ & $\mathrm{R} \$ 39.235,75$ & 6,65 & $\mathrm{R} \$ 1.047,04$ & 9,82 \\
\hline $\begin{array}{l}\text { VII - DOENÇAS DO OLHO E } \\
\text { ANEXOS }\end{array}$ & $\mathrm{R} \$ 9.004,07$ & 0,50 & $\mathrm{R} \$ \quad 770,26$ & 1,02 \\
\hline VIII - DOENÇAS DO OUVIDO E & $\mathrm{R} \$ 6.377,73$ & 2,20 & $\mathrm{R} \$ 2.281,94$ & 3,54 \\
\hline
\end{tabular}


Artigo de Revisão

Hegemonia - Revista Eletrônica do Programa de Mestrado em Direitos Humanos, Cidadania e Violência/Ciência Política do Centro Universitário Unieuro

ISSN: $1809-1261$

UNIEURO, Brasília, número 27 (Especial), 2019, pp. 128-160.

\begin{tabular}{|c|c|c|c|c|}
\hline \multicolumn{5}{|l|}{ DA APÓFISE MASTÓIDE } \\
\hline $\begin{array}{l}\text { IX - DOENÇAS DO APARELHO } \\
\text { CIRCULATÓRIO }\end{array}$ & $\mathrm{R} \$ 29.400,73$ & 4,97 & $\mathrm{R} \$ 2.408,21$ & 9,44 \\
\hline $\begin{array}{l}\mathrm{X} \text { - DOENÇAS DO APARELHO } \\
\text { RESPIRATÓRIO }\end{array}$ & $\mathrm{R} \$ 27.709,50$ & 5,70 & $\mathrm{R} \$ 1.159,81$ & 7,64 \\
\hline $\begin{array}{l}\text { XI - DOENÇAS DO APARELHO } \\
\text { DIGESTIVO }\end{array}$ & $\mathrm{R} \$ 16.957,27$ & 3,08 & $\mathrm{R} \$ 1.086,87$ & 5,68 \\
\hline $\begin{array}{l}\text { XII - DOENÇAS DA PELE E DO } \\
\text { TECIDO CELULAR SUBCUTÂNEO }\end{array}$ & $\mathrm{R} \$ 47.682,38$ & 8,28 & $\mathrm{R} \$ \quad 458,77$ & 6,73 \\
\hline $\begin{array}{l}\text { XIII - DOENÇAS DO SISTEMA } \\
\text { OSTEOMUSCULAR E DO TECIDO } \\
\text { CONJUNTIVO }\end{array}$ & $\mathrm{R} \$ 28.481,41$ & 2,75 & $\mathrm{R} \$ 1.583,81$ & 7,53 \\
\hline $\begin{array}{l}\text { XIV - DOENÇAS DO APARELHO } \\
\text { GENITURINÁRIO }\end{array}$ & $\mathrm{R} \$ 15.927,14$ & 3,68 & $\mathrm{R} \$ \quad 824,78$ & 6,04 \\
\hline $\begin{array}{l}\text { XV - GRAVIDEZ, PARTO E } \\
\text { PUERPÉRIO }\end{array}$ & $\mathrm{R} \$ 6.731,95$ & 1,94 & $\mathrm{R} \$ \quad 590,84$ & 3,32 \\
\hline $\begin{array}{l}\text { XVI - ALGUMAS AFECÇÕES } \\
\text { ORIGINADAS NO PERİODO } \\
\text { PERINATAL }\end{array}$ & $\mathrm{R} \$ 13.061,87$ & 5,59 & $\mathrm{R} \$ 1.121,90$ & 7,54 \\
\hline $\begin{array}{l}\text { XVII - MALFORMAÇÕES } \\
\text { CONGÊNITAS, DEFORMIDAS E } \\
\text { ANOMALIAS CROMOSSÔMICAS }\end{array}$ & - & - & $\mathrm{R} \$ 3.250,45$ & 7,85 \\
\hline $\begin{array}{l}\text { XVIII - SINTOMAS, SINAIS E } \\
\text { ACHADOS ANORMAIS DE } \\
\text { EXAMES CLÍNICOS E DE } \\
\text { LABORATÓRIO, NÃO } \\
\text { CLASSIFICADOS EM OUTRA } \\
\text { PARTE }\end{array}$ & $\mathrm{R} \$ 16.959,84$ & 4,24 & 463,16 & 3,87 \\
\hline $\begin{array}{l}\text { XIX - LESÕES, } \\
\text { ENVENENAMENTOS E } \\
\text { ALGUMAS OUTRAS } \\
\text { CONSEQUÊNCIAS DE CAUSAS } \\
\text { EXTERNAS E XX - CAUSAS } \\
\text { EXTERNAS DE MORBIDADE E } \\
\text { DE MORTALIDADE }\end{array}$ & $\mathrm{R} \$ 29.263,80$ & 3,69 & $\mathrm{R} \$ 1.135,59$ & 7,93 \\
\hline $\begin{array}{l}\text { XXI - FATORES QUE } \\
\text { INFLUENCIAM O ESTADO DE } \\
\text { SAÚDE E O CONTATO COM OS } \\
\text { SERVIÇOS DE SAÚDE }\end{array}$ & $\mathrm{R} \$ 12.459,02$ & 1,98 & 738,58 & 2,73 \\
\hline
\end{tabular}

Fonte: Relatórios da operadora de autogestão, e DATASUS, 2017.

As internações por DAC, quando comparadas na operadora de autogestão e no SUS, possuem quase o dobro da média de diárias por internações no SUS (9,44 dias para 4,97 dias na autogestão), e, custo médio por internação, a autogestão gasta dez vezes mais que o SUS. De tal modo, os procedimentos realizados nos pacientes de cada sistema, são de tecnologias diferentes, utilizando, no sistema privado, tecnologias mais recentes e consequentemente de maior custo.

Segundo o Saúde Brasil (Brasil, 2015a), as DAC têm a maior carga de mortalidade prematura (entre 30 a 69 anos de idade). Ou seja, além de ser a principal causa de internações no país, também lideram as causas de óbito. As DAC são seguidas pelas neoplasias, doenças respiratórias crônicas e o diabetes, como causas de óbitos. O padrão analisado, reflete a morbimortalidade no país. 
Artigo de Revisão

Hegemonia - Revista Eletrônica do Programa de Mestrado em Direitos Humanos, Cidadania e Violência/Ciência Política do Centro Universitário Unieuro

ISSN: 1809-1261

UNIEURO, Brasília, número 27 (Especial), 2019, pp. 128-160.

As causas de internações no Brasil, são fatores pouco estudados, principalmente no que tange aos capítulos do CID. As principais e mais recentes pesquisas, são enfatizadas nas faixas etárias da população, a exemplo idosos. Filho et al (2004), mostra que as doenças do aparelho circulatório, respiratório e digestivo foram responsáveis, no período estudado, por $60 \%$ das internações, no SUS. Na população jovem, essas causas representaram apenas 38\% das internações.

Em quase todos os Capítulos do CID-10 analisados, é perceptível que no Sistema Único de Saúde, os gastos são reduzidos, embora haja maior permanência do usuário no serviço hospitalar. Destacam-se os Capítulos II - Neoplasias e o Capítulo XIV - Doenças do aparelho Geniturinário.

As Neoplasias, apresentam custo elevado para ambos sistemas de saúde, porém a média de custos na autogestão, é superior ao SUS. A média de internações, também é outro fator relevante, onde o beneficiário da autogestão, fica em média 1,68 dia para receber o atendimento e/ou tratamento, enquanto o usuário do Sistema Único de Saúde, tem média de 7,90 dias. Esse comportamento, permite inferir que há atendimento mais eficaz, com utilização de maior densidade tecnológica.

Para que uma tecnologia seja incorporada, alterada ou excluída do SUS, é necessário que haja aprovação pela Comissão Nacional de Incorporação de Tecnologias no Sistema Único de Saúde - CONITEC. Essa incorporação, depende da submissão de empresas ou usuários interessados, e de evidências científicas que comprovem a eficácia da tecnologia, e a análise do impacto que essa incorporação causará ao SUS (Brasil, 2011).

No sistema privado de saúde, a inclusão de tecnologias, tem menor burocracia, visto que o público a ser atendido é menor, e a disponibilização da tecnologia, não está em nível nacional. As inovações tecnológicas no SUS, tem incorporação lenta e também não exclui a utilização das tecnologias já presentes no sistema para o cuidado do usuário.

O outro Capítulo CID-10 que se destaca quanto aos custos e baixa permanência no sistema de autogestão, é Capítulo XIV - Doenças do aparelho geniturinário, com custo médio de quase dezesseis mil reais, para 3,68 dias de internação. No SUS, o gasto com o paciente é de em média 824,78 reais por internação, com permanência média no serviço de saúde de 6,04 dias. Os principais agravos desse capítulo, identificados em Santa Catarina no plano estadual em 2000, foram as síndromes nefríticas agudas, doenças glomerulares e as doenças renais.

No capítulo "V - Transtornos mentais e comportamentais" as taxas encontradas de internações, são maiores que as observadas no SUS. Como a causa das internações não foi 
Artigo de Revisão

Hegemonia - Revista Eletrônica do Programa de Mestrado em Direitos Humanos, Cidadania e Violência/Ciência Política do Centro Universitário Unieuro

ISSN: 1809-1261

UNIEURO, Brasília, número 27 (Especial), 2019, pp. 128-160.

analisada, um fator que pode influenciar as internações por transtornos mentais e comportamentais é o abuso de substâncias químicas. Passos (2011), fala sobre as internações no DF decorrentes do uso de substâncias psicoativas, sendo que $92 \%$ das internações, eram da faixa etária de 20 a 59 anos. Outro fator ressaltado pela autora, é o acompanhamento realizado pelos Centros de Apoio Psicossociais (CAPS), onde não há internação do usuário. No sistema de autogestão, a média dos custos das internações pelo CID "V", custa setenta e cinco vezes mais que no SUS.

As Doenças do olho e anexos - Capítulo VII, salienta o baixo tempo de internação e o alto custo do procedimento. Para a autogestão, o custo dos procedimentos é em média nove mil reais, entretanto, a internação não chega a média de um dia (0,5 dia). Para o SUS, a intervenção é menos onerosa, custando cerca de 800 reais, porém o usuário tem a média de um dia por internação.

Para o Banco de Olhos do Ministério da Saúde, um dos principais agravantes para esse capítulo CID-10, é a catarata, que tem maior incidência em idosos, porém é uma cirurgia com maior custo efetividade para reabilitação de pessoas com idade avançada (Brasil, 2013). Na autogestão, esse capítulo apresentou apenas quatro internações no período analisado, mostrando o alto custo das tecnologias empregadas no sistema.

Apesar de haver financiamento oriundo da mesma fonte, a administração da verba recebida difere para cada sistema, principalmente no que tange ao tamanho de cada um, dificultando, no SUS, uma gestão eficiente. As proporções dos sistemas de saúde, e o público assistido, são fatores que influenciam a eficiência do serviço.

Ante o exposto, é visível que o plano de saúde de autogestão, possui formas menos burocráticas de oferecer atendimentos com tecnologias mais recentes aos seus beneficiários, outro fator, é ter um número reduzido de pessoas para atender, fato que possibilita procedimentos mais caros. Como o custo da internação é maior, e a tecnologia é mais nova, o período de permanência desse beneficiário no serviço de saúde é reduzido, podendo sua recuperação também ser mais rápida. Esse fator, contribui para a satisfação do beneficiário com o cuidado em saúde.

Enquanto isso, no SUS, o custo das intervenções é mais baixo, de tal forma, as tecnologias utilizadas também tem menor custo, visto o fato que, quando há incorporação da mesma no sistema, é necessário a comprovação de que será um procedimento eficiente com custo que valha a pena sua inserção. Outro fator de relevância, é o tempo de permanência que o usuário tem no sistema público, sendo o dobro na maioria dos casos. 
Artigo de Revisão

Hegemonia - Revista Eletrônica do Programa de Mestrado em Direitos Humanos, Cidadania e Violência/Ciência Política do Centro Universitário Unieuro

ISSN: $1809-1261$

UNIEURO, Brasília, número 27 (Especial), 2019, pp. 128-160.

A permanência aumentada, pode causar possíveis iatrogenias ao paciente, fazendo com que o mesmo se torne suscetível a adquirir outros agravos. Já o sistema de saúde, perde em custo, com a internação prolongada, visto que aquele indivíduo que não recebe a atenção adequada, ocupe mais tempo o leito, e impede a internação de outros indivíduos que também necessitam de cuidado.

\section{CONSIDERAÇÕES FINAIS}

O financiamento do SUS sofre com repasse inadequado à outras instituições de saúde, mesmo que a contribuição à saúde privada esteja permitida na legislação. Entretanto, a saúde privada deve agir em caráter suplementar, mas nota-se que o sistema privado, que atende menor parte da população brasileira, recebe maior repasse financeiro.

Isso agrega dificuldades na prestação de serviço que seja satisfatório ao usuário do sistema público, visto que seu tempo de permanência no serviço e de recuperação é diretamente afetado, principalmente quando há necessidade de exames complementares para o prognóstico do paciente.

Embora a cobertura do sistema público não esteja atendendo à toda população de maneira satisfatória, é válido salientar que o SUS é uma política de Estado nova e que está em constante mudança, visando cumprir o determinado na Constituição Federal.

Entretanto, o serviço de autogestão oferece um tratamento satisfatório, no que tange à permanência do usuário no serviço hospitalar, sendo necessário poucos dias para que haja o atendimento e recuperação do beneficiário. A análise de ambos sistemas, não deve qualificar ou desqualificá-los, pois cada um atende uma população diferenciada, com necessidades específicas.

Pode-se enfatizar também, que ainda que exista grande repasse financeiro ao sistema de autogestão, o sistema poderia não atender a população e o serviço de saúde não fazer jus ao que é pago, como acontece com o SUS. Mesmo com alto custo, a população tem vantagem em adquirilo, pois a cobertura, o atendimento e o tempo de permanência no serviço hospitalar são satisfatórios para o beneficiário.

A comparação entre os dois sistemas de saúde, deixa claro como a política deve ser alterada, visando o bem da maior parte da população brasileira, e reduzindo ou eliminando o subfinanciamento do SUS.

Há necessidade, de elaboração de estudos que possam verificar a qualidade dos serviços de saúde, do ganho que o usuário tem ou não, quando opta por escolher entre algum sistema para ter assistência à saúde. 
Artigo de Revisão

Hegemonia - Revista Eletrônica do Programa de Mestrado em Direitos Humanos, Cidadania e Violência/Ciência Política do Centro Universitário Unieuro

ISSN: $1809-1261$

UNIEURO, Brasília, número 27 (Especial), 2019, pp. 128-160.

O profissional sanitarista sabe reconhecer e atuar nesses dois sistemas para que sejam efetivos e adequados, e que a população ganhe na qualidade do atendimento, seja ele ambulatorial ou hospitalar, reduzindo os agravos na saúde.

A melhoria no financiamento de ambos sistemas, depende de estudos com maiores detalhamentos, entretanto, não devem ser julgadas apenas a modalidade de autogestão, mas todas que foram citadas no trabalho.

\section{REFERÊNCIAS BIBLIOGRÁFICAS}

Associação Brasileira para o Estudo da Obesidade e da Síndrome Metabólica - ABESO. Diretrizes brasileiras de obesidade 2009/2010. 3.ed. - Itapevi, SP: AC Farmacêutica, 2009.

ANS, Agência Nacional de Saúde Suplementar. Dados Gerais. Disponível em <http://www.ans.gov.br/perfil-do-setor/dados-gerais>. Acesso em março, 2017.

BRASIL. Lei n. 4.320 de 17 de março de 1964. Estatui Normas Gerais de Direito Financeiro para elaboração e controle dos orçamentos e balanços da União, dos Estados, dos Municípios e do Distrito Federal.

Constituição da República Federativa do Brasil: texto constitucional promulgado em 5 de outubro de 1988, com as alterações determinadas pelas Emendas Constitucionais de Revisão nos 1 a 6/94, pelas Emendas Constitucionais nos 1/92 a 91/2016 e pelo Decreto Legislativo no 186/2008. - Brasília: Senado Federal, Coordenação de Edições Técnicas, 2016.

Lei n. 8.080 de 19 de setembro de 1990. Dispõe sobre as condições para a promoção, proteção e recuperação da saúde, a organização e o funcionamento dos serviços correspondentes e dá outras providências.

Lei n. 9.656, de 3 de junho de 1998. Dispõe sobre os planos e seguros privados de assistência à saúde.

Lei n. 9.961 de 28 de janeiro de 2000a. Cria a Agência Nacional de Saúde Suplementar ANS e dá outras providências.

Agência Nacional de Saúde Suplementar. Resolução de Diretoria Colegiada - RDC n. 39, 
Artigo de Revisão

Hegemonia - Revista Eletrônica do Programa de Mestrado em Direitos Humanos, Cidadania e Violência/Ciência Política do Centro Universitário Unieuro

ISSN: 1809-1261

UNIEURO, Brasília, número 27 (Especial), 2019, pp. 128-160.

de 27 de outubro de 2000b. Dispõe sobre a definição, a segmentação e a classificação das Operadoras de Planos de Assistência à Saúde.

Agência Nacional de Saúde Suplementar. Resolução Normativa - RN n. 137, de 14 de novembro de 2006. Dispõe sobre as entidades de autogestão no âmbito do sistema de saúde suplementar.

. Agência Nacional de Saúde Suplementar. Resolução Normativa - RN n. 148, de 3 de março de 2007. Altera a Resolução Normativa - RN no 124, de 30 de março de 2006; a RN no 128, de 18 de maio de 2006; a RN no 129, de 18 de maio de 2006; a $\mathrm{RN}$ n$^{\circ}$ 137, de 14 de novembro de 2006; a RN no 94, de 23 de março de 2005; a RN no 112, de 28 de agosto de 2005; a $\mathrm{RN} \mathrm{n}$ (67, de 4 de fevereiro de 2004; a $\mathrm{RN}$ n$^{\circ}$ 26, de 1 de abril de 2003; a $\mathrm{RN}$ n$^{\circ}$ 19, de 11 de dezembro de 2002; e a Resolução de Diretoria Colegiada - RDC nº 77, de 17 de julho de 2001.

- Ministério da Saúde. Morbidade Hospitalar do SUS por causas externas por local de internação: Notas técnicas. Portaria Geral do Ministério da Saúde n. 321 de 08 de fevereiro de 2007. Institui a Tabela de Procedimentos, Medicamentos, Órteses/Próteses e Materiais Especiais - OPM do Sistema Único de Saúde - SUS.

. Agência Nacional de Saúde Suplementar. Resolução Normativa - RN n. 196, de 14 de julho de 2009. Dispõe sobre a Administradora de Benefícios.

Lei n. 14.401 de 28 de abril de 2011. Altera a Lei no 8.080, de 19 de setembro de 1990, para dispor sobre a assistência terapêutica e a incorporação de tecnologia em saúde no âmbito do Sistema Único de Saúde - SUS. 2011.

Agência Nacional de Saúde Suplementar. Resolução Normativa - RN n. 315, de 28 de novembro de 2012. Altera as Resoluções Normativas - $\mathrm{RN} \mathrm{n}^{\circ}$ 85, de 7 de dezembro de 2004, que dispõe sobre a concessão de Autorização de Funcionamento das operadoras de planos de assistência à saúde, e dá outras providências, $\mathrm{RN} \mathrm{n}^{\circ} 137$, de 14 de novembro de 2006, que dispõe sobre as entidades de autogestão no âmbito do sistema de saúde suplementar, e Resolução de Diretoria Colegiada - RDC n ${ }^{\circ}$ 39, de 27 de outubro de 2000, que dispõe sobre a definição, a segmentação e a classificação das Operadoras de Planos de Assistência à Saúde. 2012a.

Resolução n. 35 de 15 de agosto de 2012. Diário Oficial da União. Brasília, 15 de agosto de 2012. Seção I, p. 2. 2012b. 
Artigo de Revisão

Hegemonia - Revista Eletrônica do Programa de Mestrado em Direitos Humanos, Cidadania e Violência/Ciência Política do Centro Universitário Unieuro

ISSN: 1809-1261

UNIEURO, Brasília, número 27 (Especial), 2019, pp. 128-160.

. Ministério da Saúde. Banco de Olhos. Desafio da Atenção à Saúde Ocular da Pessoa Idosa.

2013. Disponível em <http://ares.hosbos.com.br/blog/materias/desafio-da-atencao-a-saudeocular-da-pessoa-idosa/>. Acesso em Novembro, 2017.

Ministério da Saúde. Secretaria de Vigilância em Saúde. Saúde Brasil 2014: uma análise da situação de saúde e das causas externas. Brasília, 2015a.

Agência Nacional de Saúde Suplementar. Estrutura de concorrência no setor de operadoras de planos de saúde no Brasil. Rio de Janeiro, 2015b.

Agência Nacional de Saúde Suplementar. Programa de Qualificação da Saúde Suplementar. Disponível em <http://www.ans.gov.br/index.php/aans/nossos-servicos/137-programa-dequalificacao-da-saude-suplementar-qualificacao-das-operadoras>. Acesso em outubro, 2016.

Biblioteca Virtual em Saúde. Proporção de internações hospitalares (SUS) por grupo de causas - D.13 - 2010. In: Características dos Indicadores - Fichas de Qualificação. Disponível em <http://fichas.ripsa.org.br/2010/d-13/>. Acesso em novembro, 2017.

- Ministério da Saúde. Vigitel Brasil 2016: vigilância de fatores de risco e proteção para doenças crônicas por inquérito telefônico: estimativas sobre frequência e distribuição sociodemográfica de fatores de risco e proteção para doenças crônicas nas capitais dos 26 estados brasileiros e no Distrito Federal em 2016. Brasília, 2017.

. Instituto Brasileiro de Geografia e Estatística - IBGE. População do Distrito Federal. Disponível em < https://cidades.ibge.gov.br/brasil/df/panorama>. Acesso em novembro, 2017. BAHIA. O sistema de saúde brasileiro entre normas e fatos: universalização mitigada e estratificação subsidiada. Ciência \& Saúde Coletiva, 2009. Disponível em < http://www.uacm.kirj.redalyc.redalyc.org/articulo.oa?id=63013535011>. Acesso em novembro, 2017.

BAHIA. SCHEFFER. Planos e Seguros de Saúde. Editora UNESP, São Paulo, 2010.

BOINO. VARGAS. BOINO. A carga das neoplasias no Brasil: Mortalidade e Morbidade Hospitalar entre 2002-2004. Revista Assoc. Med. Bras. 2007.

CASTRO. TRAVASSOS. CARVALHO. Fatores associados às internações hospitalares no Brasil. Ciência e Saúde Coletiva. 2002, p. 795-811. 
Artigo de Revisão

Hegemonia - Revista Eletrônica do Programa de Mestrado em Direitos Humanos, Cidadania e Violência/Ciência Política do Centro Universitário Unieuro

ISSN: 1809-1261

UNIEURO, Brasília, número 27 (Especial), 2019, pp. 128-160.

COSTA. BARRETO. Tipos de estudos epidemiológicos: conceitos básicos e aplicações na área do envelhecimento. Epidemiologia e Serviços de Saúde 2003; 12(4): 189 - 201.

DIAS. A informação na regulação da saúde suplementar. Fundação Oswaldo Cruz. 2004.

ELIAS. Sistema de Saúde no Brasil. Departamento de Medicina Preventiva, Universidade de São Paulo. São Paulo, 2005. Disponível na internet < http://fm.usp.br/cedem/did/atencao/4-\%20Bibliografia \%20Complementar\%20-\%20Sistema\% 20de $\% 20 \mathrm{Sa} \%$ C3\%BAde $\% 20$ no $\% 20$ Brasil\%20FINAL.pdf $>$, acesso em outubro, 2016.

FRANCO. O método PES: entrevista com Matus. Trad. Giselda Barroso Sauveur. São Paulo: Fundap, 1996.

FILHO, et al. Causas de internações hospitalares entre idosos brasileiros no âmbito do Sistema Único de Saúde. Epidemiologia e Serviços de Saúde, 2004.

GÓIS, VERAS. Informações sobre a morbidade hospitalar em idosos nas internações do Sistema Único de Saúde do Brasil. Ciência \& Saúde Coletiva. 2010.

JORGE. KOIZUMI. TONO. Causas externas: o que são, como afetam o setor saúde, sua medida e alguns subsídios para a sua prevenção. Revista Sua Saúde. Universidade de Guarulhos. 2007.

MENDES. Os sistemas de atenção à saúde: os sistemas fragmentados e as redes de atenção à saúde. In: As redes de atenção à saúde. Brasília: Organização Pan-Americana da Saúde, 2011.

ORGANIZAÇÃO MUNDIAL DA SAÚDE - OMS. CID-10 Classificação Estatística Internacional de Doenças e Problemas Relacionados à Saúde. 10a rev. São Paulo: Universidade de São Paulo; 1997. vol.1.

OLIVEIRA. Diagnóstico das internações hospitalares por doenças respiratórias em Uberlândia (MG). X Fórum Ambiental da Alta Paulista, v. 10, n. 12, 2014, pp. 93-103.

PAIM. Modelos de atenção à saúde no Brasil. In: GIOVANELLA et al (orgs.). In: GIOVANELLA et al (orgs.). Políticas e Sistema de Saúde no Brasil. Rio de Janeiro: Fiocruz, 2008. p. 547-573.

PAIVA. TEIXEIRA. Reforma sanitária e a criação do Sistema Único de saúde: notas sobre contextos e autores. Histórica, Ciências, Saúde. Rio de Janeiro. v.21, n.1, jan.-mar. 2014, p.15-35.

PASSOS. Internações decorrentes do uso de substâncias psicoativas no Distrito Federal entre os 
Artigo de Revisão

Hegemonia - Revista Eletrônica do Programa de Mestrado em Direitos Humanos, Cidadania e Violência/Ciência Política do Centro Universitário Unieuro

ISSN: 1809-1261

UNIEURO, Brasília, número 27 (Especial), 2019, pp. 128-160.

anos de 2000 a 2009. Fundação Oswaldo Cruz. Brasília, 2011.

PIETROBON. PRADO. CAETANO. Saúde suplementar no Brasil: o papel da Agência Nacional de Saúde Suplementar na regulação do setor. Revista de Saúde Coletiva, Rio de Janeiro, 18 [ 4 ]: 767-783, 2008.

PILGER, et al. Causas de internação hospitalar de idosos residentes em um município do Paraná, uma análise dos últimos 5 anos. Revista de Enfermagem. UFSM. 2011.

R Core Team (2017). R: A language and environment for statistical computing. R Foundation for Statistical Computing, Vienna, Austria. URL < https://www.R-project.org/>.

SESTELO. BAHIA. Sistema de Assistência Médica Suplementar (SAMS): Breve histórico e modalidades desenvolvidas no Brasil. In PAIM, ALMEIDA FILHO. Saúde coletiva: teoria e prática. 1 ed. Rio de Janeiro, 2014.

SILVEIRA, et al. Gastos relacionados a hospitalizações de idosos no Brasil: perspectivas de uma década. Einstein, 2013.

UNIDAS. Pesquisa Nacional UNIDAS 2016. São Paulo, 2016.

UNIDAS. Autogestão em saúde: quem somos. Disponível em $<$ https://www.unidas.org.br/institucional/apresentacao>. Acesso em novembro, 2017.

VASCONCELOS. GOMES. Transição demográfica: a experiência brasileira. Epidemiologia Serviços de Saúde. Brasília, 2012.

VIEIRA, et al. Ocorrência de internações hospitalares por doenças do aparelho circulatório no estado da Bahia. Revista Pesquisa em Fisioterapia. Maio, 2016, p. 115-123.

WICKHAM et al. dplyr: A Grammar of Data Manipulation. R package version 0.7.4. https://CRAN.R-project.org/package=dplyr. 2017. 